\title{
Glutamate and Non-Glutamate Receptor Mediated Toxicity Caused by Oxygen and Glucose Deprivation in Organotypic Hippocampal Cultures
}

\author{
D. W. Newell, A. Barth, V. Papermaster, and A. T. Malouf \\ Department of Neurological Surgery, University of Washington, School of Medicine, Seattle, Washington 98195
}

In vitro ischemia models have utilized oxygen, or oxygen and glucose deprivation to simulate ischemic neuronal injury. Combined oxygen and glucose deprivation can induce neuronal damage which is in part mediated through NMDA receptors. Severe oxygen deprivation alone however can cause neuronal injury which is not NMDA mediated. We tested the hypothesis that NMDA, or non-NMDA receptor mediated mechanisms may predominate, to induce neuronal injury following severe oxygen deprivation depending on the presence of glucose. We found that NMDA receptor blockade using dizocilpine (MK-801), DL-2amino-5-phosphonovaleric acid (APV), or CGS 19755, was highly effective in reducing CA1 injury in organotypic hippocampal cultures, caused by complete oxygen and glucose deprivation. Complete oxygen deprivation alone however, caused CA1 neuronal injury which was not diminished using NMDA receptor blockade alone with MK-801 or APV, or in combination with AMPA/kainate receptor blockade using 6-cyano-7-dinitroquinoxalone-2,3-dione (CNQX). Neuronal protective strategies which act primarily through non-glutamate dependent mechanisms, including hypothermia, low chloride and calcium, and the free radical scavenger, $\alpha$-phenyl-tert-butyl nitrone (PBN), provided neuronal protection against complete oxygen, as well as combined oxygen/glucose deprivation. Raising the $\mathrm{pH}$ using Hepes buffer during complete oxygen deprivation did not result in neuronal protection by NMDA receptor blockade. Partial oxygen deprivation alone, partial oxygen deprivation combined with glucose deprivation, glucose deprivation alone, and also glutamate exposure, all produced neuronal damage that was reduced by NMDA receptor blockade. The presence of glucose during complete oxygen deprivation appears to prevent glutamate receptor blockade from reducing neuronal injury in organotypic hippocampal cultures.

[Key words: glutamate, NMDA receptors, anoxia, hypoglycemia, ischemia, hypothermia, organotypic hippocampal cultures]

\footnotetext{
Received May 31, 1995; revised Aug. 1, 1995; accepted Aug. 2, 1995

We thank Paul Schwartz and Janet Clardy for preparing the illustrations and also Lois Downey for assistance with the statistical analysis. This work was supported through a grant from the National Stroke Association (D.W.N.), and also through Clinician Investigator Development Award 1 K08 NS 01596901 (D.W.N.), and NIH Grants 1 P50 NS 30305-01 (D.W.N., A.T.M.), and NS28650 (A.T.M.).

Correspondence should be addressed to David W. Newell, Department of Neurological Surgery, 3259 th Avenue, Seattle, WA 98104

Copyright $\odot 1995$ Society for Neuroscience $0270-6474 / 95 / 157702-10 \$ 05.00 / 0$
}

There is strong evidence that glutamate, which is known to be neurotoxic, contributes to ischemia induced neuronal injury (Buchan, 1990; Choi, 1990; Meldrum, 1990; Seisjo, 1992). In vivo studies have shown increases in extracellular glutamate in the brain during transient forebrain ischemia, and also following head injury (Benveniste et al., 1984; Faden et al., 1989; Katayama et al., 1990). Interruption of glutamatergic neuronal connections to hippocampal CA1 cells prior to transient forebrain ischemia can provide protection against $\mathrm{CA} 1$ ischemic damage suggesting that synaptic release of glutamate plays a role (Johansen et al., 1986; Ondera et al., 1986; Jorgenson et al., 1987). Moreover, glutamate receptor blockade of the NMDA and the non-NMDA subtypes can reduce neuronal damage following focal ischemia (Germano et al., 1987; Meldrum, 1990) and transient forebrain ischemia (Gill et al., 1987; Buchan et al., 1991). Recently, however, NMDA antagonists have not prevented CA1 damage following transient forebrain ischemia when the experiments were controlled for temperature (Buchan, 1990; Buchan and Pulsinelli, 1990). Glutamate receptor blockade can also protect dissociated neuronal cultures from damage induced by combined oxygen and glucose deprivation (Goldberg and Choi, 1993; Kaku et al., 1993).

The evidence for glutamate mediated damage following oxygen deprivation alone, is less convincing. Some investigators have reported reduced neuronal injury from oxygen deprivation using glutamate antagonists in dissociated cell cultures (Goldberg et al., 1987; Marcoux et al., 1990), or in acutely prepared hippocampal slices (Clark and Rothman, 1987). Other investigators have reported that glutamate receptor antagonists do not effectively reduce neuronal damage following oxygen deprivation alone (Aitken et al., 1988; Lipton and Lobner, 1990; Schurr and Rigor 1992; Friedman and Haddad, 1993; Haddad and Jiang, 1993). These previous studies raise the possibility that the nature and severity of the insult which is used to cause energy deprivation in these models may activate glutamate or non-glutamate receptor dependent mechanisms which in turn lead to neuronal damage.

We utilized organotypic hippocampal slice cultures to examine neuronal protection from different severities of oxygen and or glucose deprivation. This model utilizes brain slices, prepared from the hippocampal formation of neonatal rats which are then maintained in a culture system for several weeks (Gahwiler, 1981; Newell et al., 1990; Vornov et al., 1994). Hippocampal slice cultures retain much of the anatomy, synaptic circuitry, and neurotransmitter receptors as the intact hippocampus (Zimmer and Gahwiler, 1984; Gahwiler, 1984, 1988; Vornov et al., 1991; Torp et al., 1992). These mature cultures are then deprived of 
Table 1. Concentrations of ions in solutions used for oxygen and glucose deprivation (mM)

\begin{tabular}{lcccc} 
& HBSS & & \multicolumn{2}{c}{$\begin{array}{l}\text { Low chloride, no } \\
\text { calcium }\end{array}$} \\
\cline { 2 - 3 } \cline { 5 - 6 } $\begin{array}{l}\text { with } \\
\text { glucose }\end{array}$ & $\begin{array}{l}\text { without } \\
\text { glucose }\end{array}$ & & $\begin{array}{l}\text { with } \\
\text { glucose }\end{array}$ & $\begin{array}{l}\text { without } \\
\text { glucose }\end{array}$ \\
\hline Sodium & 142 & 142 & 143 & 143 \\
Potassium & 5.3 & 5.3 & 5.3 & 5.3 \\
Chloride & 145 & 145 & 5.5 & 5.5 \\
Sulfate & 0.4 & 0.4 & 0.4 & 0.4 \\
Calcium & 1.3 & 1.3 & 0 & 0 \\
Magnesium & 0.9 & 0.9 & 0.9 & 0.9 \\
Phosphate & 0.6 & 0.6 & 0.6 & 0.6 \\
Glucose & 33.6 & 0 & 33.6 & 0 \\
Sucrose & 29 & 63 & 29 & 63 \\
Bicarbonate & 4.0 & 4.0 & 4.0 & 4.0 \\
Gluconate & 0 & 0 & 139 & 139
\end{tabular}

Data indicate the ionic concentrations of the solutions used during exposure of the cultures to different insults. Additional oxygen deprivation experiments described were performed in HBSS with glucose, using a lower glucose concentration $(5.6 \mathrm{mM})$ and a higher sucrose concentration $(57 \mathrm{mM})$ than the concentrations described above.

oxygen and or glucose and subsequent cell death can be assessed (Newell et al., 1990, 1995; Hsu et al., 1994).

We found a strong neuroprotective effect of NMDA receptor blockade on CA1 damage in organotypic hippocampal slice cultures, following combined oxygen and glucose deprivation; however, no protective effect of NMDA, and/or AMPA/kainate receptor blockade following severe oxygen deprivation alone. We also studied the effects neuroprotective strategies including hypothermia, decreased extracellular chloride and calcium concentration, and a free radical scavenger $\alpha$-phenyl-tert-butyl nitrone $(\mathrm{PBN})$, on neuronal damage induced by oxygen deprivation alone, and combined oxygen and glucose deprivation. In addition we examined potential role of $\mathrm{pH}$ in mediating the lack of effectiveness of NMDA blockade in reducing neuronal injury following severe oxygen deprivation.

\section{Materials and Methods}

Preparation of cultures. Organotypic cultures of the hippocampus were prepared according to the method of Stoppini et al. (1991). Hippocampal slices were prepared from 4-7 d old neonatal rats (Sprague-Dawley; Bantin and Kingman Inc., Fremont, CA) by removing the brain, dissecting the hippocampal formation and making transverse slices (400$500 \mu \mathrm{m}$ ) using a McIlwain tissue slicer. Slices were then placed in Gey's balanced salt solution supplemented with glucose (final concentration $6.5 \mathrm{mg} / \mathrm{ml}$, or $33.6 \mathrm{~mm}$ ), for $1 \mathrm{hr}$ at $4^{\circ} \mathrm{C}$. Individual slices were then transferred to $28 \mathrm{~mm}$ sterile transparent Anocel membranes (Whatman Inc., Clifton, NJ). Membranes were placed in 6 well culture trays with $1.5 \mathrm{ml}$ growth medium consisting of 50\% MEM (GIBCO Laboratories, Grand Island, NY) supplemented with Hepes and sodium bicarbonate, $25 \%$ Hanks' balanced salt solution, $25 \%$ horse serum, and glucose to a final concentration of $6.5 \mathrm{mg} / \mathrm{ml}$. The cultures were then grown at $36.5^{\circ} \mathrm{C}, 90-100 \%$ humidity, $5 \% \mathrm{CO}_{2}$. Antibiotics were not added to the medium. The culture medium was changed every $2 \mathrm{~d}$. All cultures used in this study were grown for 10-14 $\mathrm{d}$ in vitro, and only those cultures with dentate, CA1, and CA3, were used. Propidium iodide (PI) (Sigma Chemical Co., St. Louis, MO), which rapidly enters cells with damaged membranes and becomes brightly fluorescent after binding to nucleic acids, was added $(0.5 \mu \mathrm{g} / \mathrm{ml})$ to the culture medium as an indicator of neuronal death during the experiment. By itself, PI is non toxic to neurons and has been used as an indicator of neuronal membrane integrity and cell viability(Macklis and Madison, 1990). After $24 \mathrm{hr}$, the cultures were examined using a Nikon Diaphot (Nikon Corp. Tokyo, Japan)

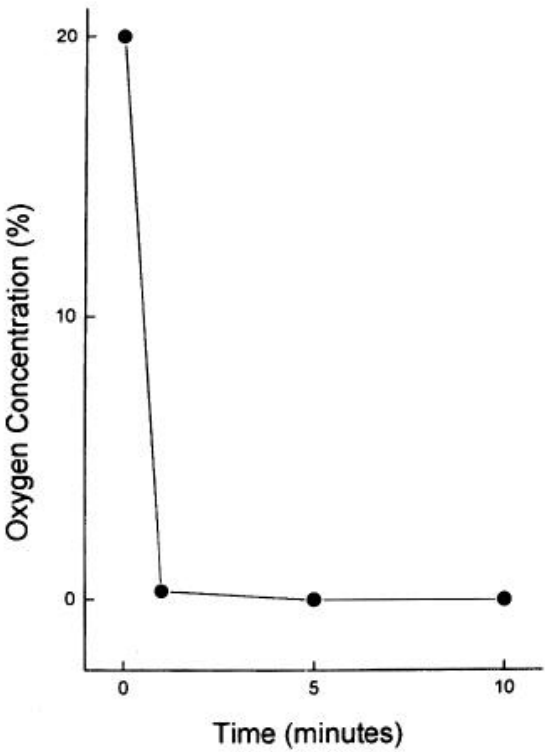

Figure 1. Example of the time course of the oxygen concentration measured at the membrane surface containing the hippocampal slice cultures, using a Clarke oxygen microelectrode. The units are given in percent oxygen concentration. The meter was set to zero in $100 \%$ nitrogen, and then calibrated at $20 \%$ in room air. The measurement at time $=0$ was taken in room air, and the first subsequent measurement was taken $1 \mathrm{~min}$ after transfer into the anaerobic chamber.

inverted fluorescent microscope to verify that the cultures were healthy prior to insult exposure. Animals were cared for according to the guidelines of the University of Washington animal care committee.

Preparation of compounds. The NMDA antagonists MK-801, APV, and the AMPA/kainate receptor antagonist CNQX were obtained from Research Biochemicals Inc., Natick, MA. The competitive NMDA antagonist CGS 19755 (Lehmann et al., 1988) was kindly provided by Ciba Geigy. $\alpha$-Phenyl-tert-butyl nitrone (PBN) was obtained from Sigma Chemical, St. Louis, MO. The compounds were prepared as a 10 mM solutions in glucose-free HBSS except CNQX which was prepared as a $5 \mathrm{~mm}$ solution. It was necessary to dissolve it first in basic conditions and then back titrate it to a neutral $\mathrm{pH}$. Each compound was added to the buffer before the insult and to the culture medium that was

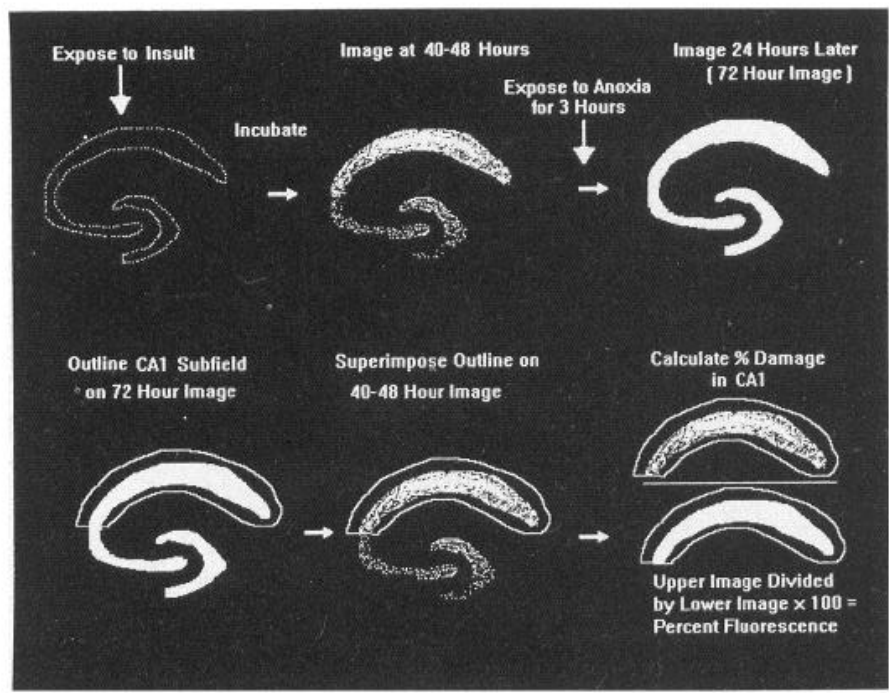

Figure 2. Illustration of the method of calulation of percent fluorescence of propidium iodide in CA1 as an index of cell damage. A detailed description of the imaging procedure is provided in the Materials and Methods section. 

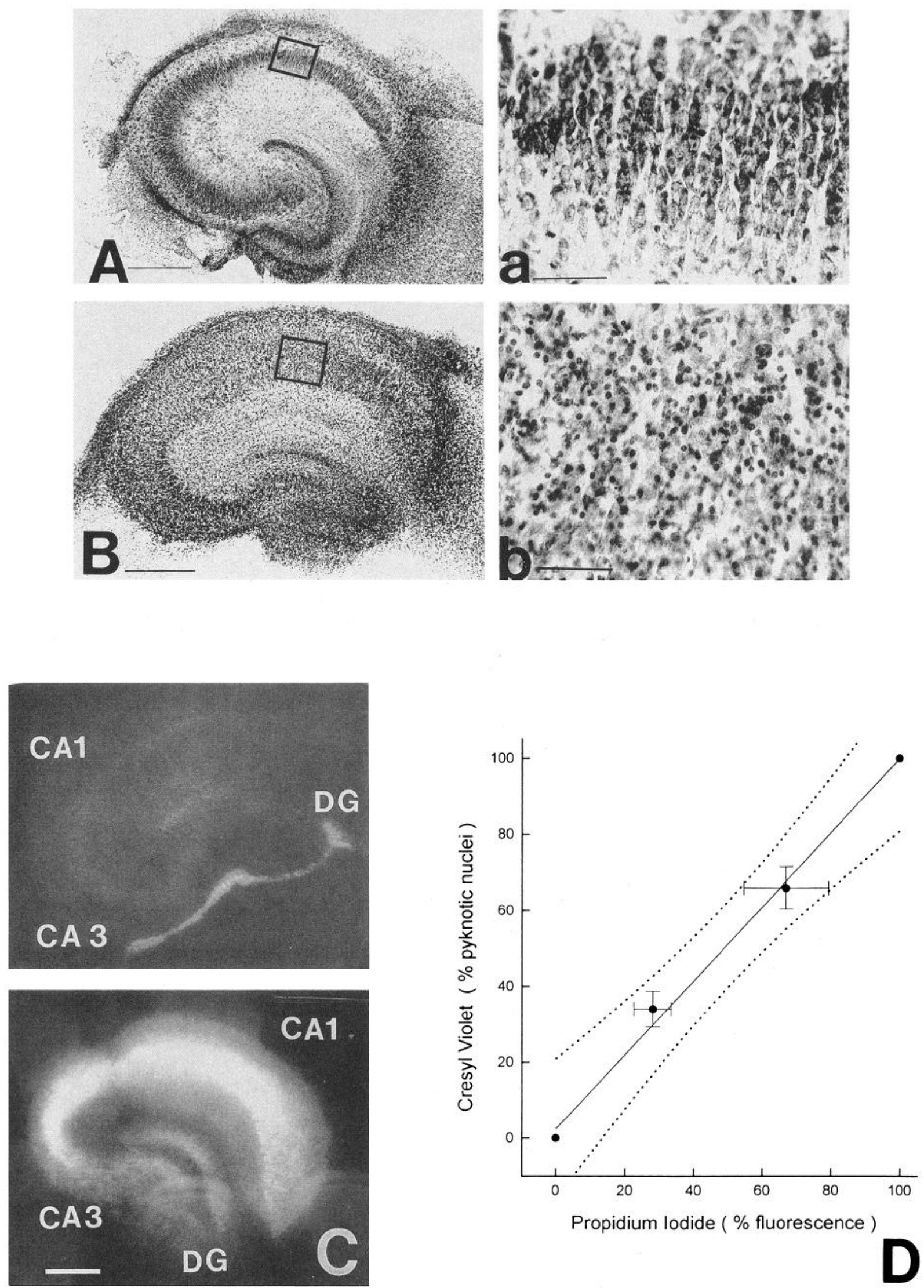

Figure 3. Comparison of cell counts to PI imaging to assess CA1 damage. Illustration of a control hippocampal slice culture (no insult). A, Low power; $B$, high power of intact CA1 pyramidal cells. Culture $2 \mathrm{~d}$ after exposure to $50 \mathrm{~min}$ of oxygen and glucose deprivation. $A$, Low power; $B$, high power of dead CA1 pyramidal cells demonstrating pyknotic nuclei, and loss of cytoplasmic architecture. Scale bars: $100 \mu \mathrm{m}$ in $1 A, 2 A ; 500$ $\mu \mathrm{m} 1 B, 2 B$ ). $C$, Propidium iodide fluorescence of slice cultures $2 \mathrm{~d}$ after exposure to either (upper) no insult, or (lower) 50 min of oxygen and glucose deprivation. $D G$, dentate gyrus. $D$, Regression analysis illustrating the results of a comparison between the cell counting method and the 
used for the incubation following the insult, as small aliquots to give the final concentrations described. For the dose-response curve, a 10 mM stock solution of MK-801 was progressively diluted in glucose-free HBSS.

Induction of neuronal damage using various insults. Insults were induced using previously described methods (Newell et al., 1990, 1995). The cultures were rinsed $3 X$ in glucose-free, or glucose containing HBSS, and then placed in $1.5 \mathrm{ml}$ of HBSS without glucose for the oxygen/glucose deprivation, or in HBSS with glucose for oxygen deprivation. All HBSS solutions were adjusted to the same molarity with sucrose. For the low chloride low calcium experiments, calcium was omitted from the HBSS and sodium gluconate was used instead of sodium chloride. The composition of the solutions used is given in Table 1. Drug or vehicle were added 10-15 min before exposure to the insult. The tcmperature of each individual culture well was confirmed to be at $37^{\circ} \mathrm{C}$ with an electronic thermometer, and was carefully controlled to be equivalent in all cultures, to ensure that the results were independent of changes in temperature. For the hypothermia experiments, the temperature of the cultures was maintained at $33.0^{\circ} \mathrm{C}$ during initial transfer to the HBSS, and during the exposure to the insult. Following the insult, the cultures were then placed in growth medium which had been warmed to $37^{\circ} \mathrm{C}$ and were incubated at this temperature for $40-48 \mathrm{hr}$ until imaging.

The cultures were transferred into an anaerobic chamber (Forma Scientific) which was preequilibrated to $37^{\circ} \mathrm{C}$ and had an atmosphere of $0 \%$ oxygen, $10 \%$ hydrogen $5 \% \mathrm{CO}_{2}$, and $85 \%$ nitrogen. The hydrogen was present for interaction with a palladium catalyst which maintained the oxygen concentration at $0 \%$. An oxygen meter which utilized a Clarke microclectrode was present at all times to confirm anoxic con ditions. Following equilibration in the medium, (for $10 \mathrm{~min}$ ) the culture tray was placed in the anaerobic chamber at $37^{\circ} \mathrm{C}$ for $35 \mathrm{~min}$. Figure 1 illustrates the measurement of the time course of the oxygen level at the interface membrane which contains the cultures.

Upon removal of the tray from the anaerobic chamber, membranes were transferred to prewarmed growth medium containing drug or vehicle in the same concentrations used for pretreatment. The growth medium also contained propidium iodide at a final concentration of $0.5 \mu \mathrm{g} /$ $\mathrm{ml}$. The cultures were transferred back to a $\mathrm{CO}_{2}$ incubator at $36.5^{\circ} \mathrm{C}$ for 40-48 hr before they were evaluated for cell death.

In cultures exposed to glutamate, either MK-801 (30 $\mu \mathrm{M})$ or an equivalent amount of buffer was added to the culture medium, $10 \mathrm{~min}$ before addition of glutamate. Glutamate was then added at a final concentration of $10 \mathrm{~mm}$ and incubated at $37^{\circ} \mathrm{C}$ for $30 \mathrm{~min}$. The cultures were then removed from this medium, rinsed, and placed in fresh growth medium containing PI and either MK-801 or buffer. The cultures were then transferred back to the $\mathrm{CO}_{2}$ incubator at $36.5^{\circ} \mathrm{C}$ for $40-48 \mathrm{hr}$ before they were evaluated for cell death, using PI fluorescence.

Assessment of cell death by image analysis using PI. The intensity of propidium iodide fluorescence in the CAl subfield of the cultures was used as an index of cell death. The first measurement of fluorescent intensity was performed between $40-48 \mathrm{hr}$, following the initial insult. The cultures were examined using a Nikon Diaphot inverted fluorescent microscope. Fluorescent images were obtained using a Dage $72 \mathrm{CCD}$ camera (Michigan City, IN), and were digitized, using optimas image analysis software (Bio-Scan, Inc., Edmonds, WA) running under Microsoft windows. Forty to $48 \mathrm{hr}$ after the initial "ischemic" insult, the remaining ncurons were killed by exposing the cultures to $3 \mathrm{hr}$ of an oxia. The fluorescent intensity, $24 \mathrm{hr}$ after $3 \mathrm{hr}$ of anoxia, was set equal to $100 \%$ damage to CA1, and was then compared to the fluorescent intensity following the initial insult. The integrated gray value (the numerical value for the fluorescent intensity) in the region of interest (ROI) was calculated by the computer and was used as an index of $100 \%$ toxicity. Computer analysis of each image was performed by creating an ROI around the CA1 pyramidal cells $24 \mathrm{hr}$ after anoxia exposure (Fig. 2). The images from the same culture taken at $48 \mathrm{hr}$ following the insult were then recalled and analyzed by superimposing the ROI which had been created from that identical region following the $3 \mathrm{hr}$ anoxia exposure. The integrated gray values (fluorescent inten- sity) from the CA1 subregion following the initial insult were then expressed as a percentage of the value obtained following $3 \mathrm{hr}$ of anoxia. The values were averaged for each group and compared. All values were expressed as mean \pm SEM. Statistical analysis of the results was performed using Student's $t$ test and the Mann-Whitney test with Bonferroni correction for multiple comparisons where appropriate. Significant differences were considered at the $p$ value $<0.05$.

Comparison of PI fluorescence and histological analysis for quantification of neuronal injury. We compared the results of histologic evaluation of neuronal damage to the amount of neuronal damage determined by the computerized imaging system in order to examine the validity of the quantification method used in this study. Groups of cultures were randomized to be assessed by either histologic evaluation or calculation of percent fluorescence using computerized imaging of propidium iodide staining ( 12 cultures in each group). Parallel groups of cultures were then exposed to either no insult, or 30,40 , or $50 \mathrm{~min}$ of anoxia/hypoglycemia in HBSS to achieve varying degrees of neuronal lanlage. The cultures were then incubated in growth medium with PI for $2 \mathrm{~d}(40 \mathrm{hr})$. All of the cultures were then imaged using the inverted fluorescent microscope, digitized, and then stored for analysis. The groups for histology were then fixed in 5\% paraformaldehyde in phosphate-buffered saline, transferred to glass cover slips and then stained using cresyl violet stain. The groups for percent fluorescence were placed in anoxic conditions at $36.5^{\circ} \mathrm{C}$ for $3 \mathrm{hr}$. These cultures were then reimaged $24 \mathrm{hr}$ after the anoxic exposure.

The C.A 1 region of each culture was examined using light microscopy. Dead pyramidal neurons were identified by characteristic pyknotic nuclei and disappearance of the normal cytoplasm and cellular architecture (Brown and Brierly, 1972). A quantitative analysis of cell death in the CA1 region of each culture was performed using a modification of the sampling method described by Bolender et al. (1991). Multiple liigh power fields were examined and internal cursors were used to delineate the cells to be counted in multiple samples of each CAl region. The number of dead cells was divided by the number of dead and live cells, and multiplied by 100 to yield a percentage of dead cells in each sample. This process was repeated for each of the cultures and the results were averaged within each group, exposed to the different durations of the insult. The percentage of dead cells derived using the cell counting method was then compared to the percent fluorescence obtained using the computerized imaging system, in parallel groups of cultures exposed to the same insults, using regression analysis. The correlation between PI fluorescence and cell counting was also performed using severe oxygen deprivation with glucose $(5.6 \mathrm{~mm}$ and also at $33.6 \mathrm{~mm}$ ), to cause CAl damage.

pH measurements. The $\mathrm{pH}$ was measured in the HBSS in each culture well in groups of cultures in the anaerobic chamber immediately following the standard exposure to complete oxygen and also oxygen/ glucose deprivation. The pH in the HBSS containing glucose was slightly lower $6.63 \pm 0.055$ versus $6.77 \pm 0.083$ in the HBSS without glucose ( $p=0.04$ using $t$ test). Measurements were performed using a calibrated $\mathrm{pH}$ microelectrode (Physitemp, Clifton, NJ) and $\mathrm{pH}$ meter (Beckman Instruments, Fullerton, CA). In a separate set of experiments, $10 \mathrm{~mm}$ Hepes buffer was added to portions of HBSS with and without glucose. The $\mathrm{pH}$ was adjusted to 7.4 prior to anoxic exposure and then measured again in each of the culture wells following exposure as described above.

\section{Results}

\section{Comparison of PI fluorescence and histological analysis}

The evaluation of CAl damage $2 \mathrm{~d}$ after a graded severity of combined oxygen and glucose deprivation was performed by either the cell counting method or the PI fluorescence method as described above. Regression analysis revealed a strong significant correlation between the two assessment methods ( $r-$ $0.99, Y=2.46+0.97 x, p=0.002$ ) (Fig. 3D). The results showed a similar correlation between PI fluorescence and his-

computerized image analysis of propidium iodide fluorescence to determine the extent of CA1 damage. Groups of cultures were exposed to either no insult (control) or 30,40, or $50 \mathrm{~min}$ of oxygen and glucose deprivation. Half of the cultures in each group ( $n=24$ for each group) were evaluated by the cell counting method, and half were evaluated using PI fluorescence. Error bars represent SEM of cell count values (horizontal) and $\%$ fluorescence (vertical). Dotted lines represent $95 \%$ confidence intervals. $r=0.99, Y=2.46+0.97 x, p=0.002$. 


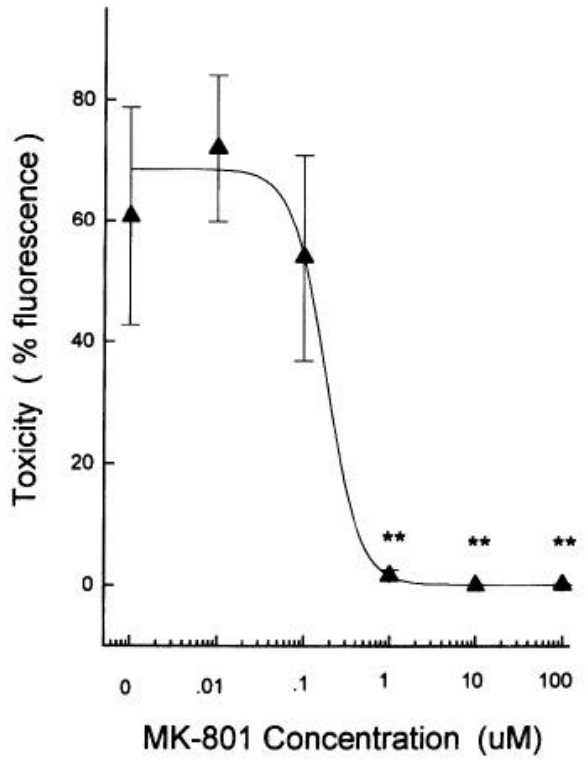

Figure 4. Dose-response curve showing the concentration-dependent reduction in neuronal injury seen with MK-801 on cultures exposed to complete oxygen and glucose deprivation (anoxia/hypoglycemia) for 35 min. (**, $p<0.01$ using Mann-Whitney $U$ test with Bonferroni correction. Control cultures compared to all others, $n=8$ for each group.)

tological damage when oxygen deprivation with glucose present, at concentrations of $33.6 \mathrm{~mm}$ and also $5.6 \mathrm{~mm}$, was used to cause the CAl damage. Oxygen deprivation with $33.6 \mathrm{~mm}$ glucose present caused CA1 damage indicated by percent dead cells and PI fluorescence as follows: after no anoxia $0 \pm 0 \%$ dead cells, $0 \pm 0 \%$ PI fluorescence, after $30 \mathrm{~min}$ anoxia $22.0 \pm 8.4 \%$ dead cells, $25.5 \pm 2.9 \%$ PI fluorescence, after $35 \mathrm{~min}, 57.9 \pm 4.7 \%$ dead cells, $53.9 \pm 9.4 \%$ PI fluorescence, and after $55 \mathrm{~min}, 100$ $\pm 0 \%$ dead cells, $99.3 \pm 1.8 \%$ PI fluorescence. Regression anal- ysis revealed the following significant correlation; $r=0.99, Y$ $=2.03+1.0 \mathrm{x}, p=0.001$.

Oxygen deprivation with $5.6 \mathrm{~mm}$ glucose present caused CA1 damage indicated by percent dead cells and PI fluorescence as follows: after no anoxia $0 \pm 0 \%$ dead cells, $0 \pm 0 \%$ PI fluorescence, after $30 \mathrm{~min}$ anoxia $18.1 \pm 2.0 \%$ dead cells, $17.6 \pm$ $6.3 \%$ PI fluorescence, after $35 \mathrm{~min}, 72.6 \pm 3.6 \%$ dead cells, $69.6 \pm 10.3 \%$ PI fluorescence, and after $55 \mathrm{~min}, 100 \pm 0 \%$ dead cells, $98.4 \pm 2.8 \%$ PI fluorescence. Regression analysis revealed the following significant correlation; $r=0.99, Y=0.3$ $+1.0 x, p=0.0002$.

\section{Complete oxygen + glucose deprivation}

NMDA receptor blockade was protective against delayed neuronal degeneration following severe oxygen $(0 \%)$ plus glucose deprivation for $35 \mathrm{~min}$. MK-801 showed CA1 protection in a dose-dependent manner (Figs. 4, 5). APV $(300 \mu \mathrm{M})$ and CGS $19755(100 \mu \mathrm{M})$ also provided significant protection from this insult (Table 2). We then investigated the protective effects of several other neuroprotective treatments, and also found significant protection against CA1 damage. These treatments included reduced temperature $\left(33^{\circ} \mathrm{C}\right)$ during the insult (hypothermia), reduced calcium and chloride in the HBSS during the insult (low calcium, low chloride, composition given in Table 1), and also treatment with the spin trapping free radical scavenger PBN (100 $\mu \mathrm{M})$ (Table 2). All of these treatments provided significant neuroprotection against CA1 damage.

\section{Complete oxygen deprivation (anoxia)}

Complete oxygen deprivation for $35 \mathrm{~min}$, produced by placing cultures in anaerobic conditions with glucose present (33.6 mM), caused damage to CA1 neurons which was not blocked by NMDA receptor blockade with MK-801 $(30 \mu \mathrm{M})$ or APV (300 $\mu \mathrm{M})$ (Fig. 5, Table 3). The same insult for a shorter time period (30 $\mathrm{min}$ ) produced less neuronal damage, and for a longer time
Figure 5. Examples of the effect of MK-801 on neuronal damage in hippocampal slice cultures in response to 35 min of oxygen and glucose deprvation (anoxia/hypoglycemia) or oxygen deprivation alone (anoxia). Illustrations of propidium iodide fluorescence $2 \mathrm{~d}$ after oxygen and glucose deprivation in a control culture (upper left), in the presence of $30 \mu \mathrm{M}$ MK-801 (lower left. Illustrations of propidium iodide fluorescence $2 \mathrm{~d}$ after complete oxygen deprivation with glucose $(33.6 \mathrm{~mm})$ present in a control culture (upper right), in the presence of $30 \mu \mathrm{M} \mathrm{MK}-801$ (lower right). DG, Dentate gyrus (white line along the bottom of the cultures is the edge of the glial envelope).
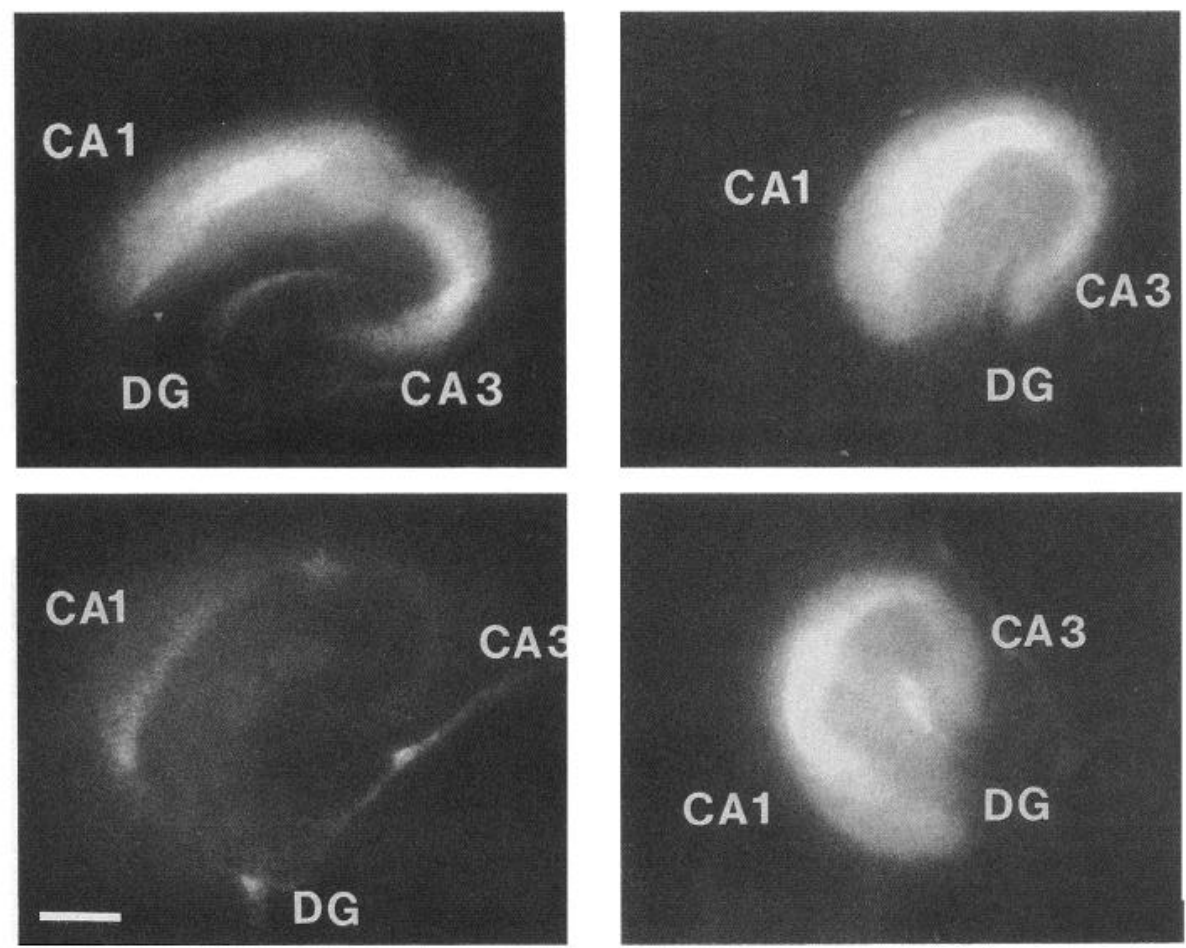
Table 2. Effect of neuroprotective strategies on CA1 damage (\% fluorescence) induced by complete oxygen and glucose deprivation

\begin{tabular}{|c|c|c|c|}
\hline & Control & Treated & $p$ value \\
\hline MK-801, $30 \mu \mathrm{M}$ & $70.1 \pm 9.7$ & $14.1 \pm 6.8$ & $<0.001$ \\
\hline APV, $300 \mu \mathrm{M}$ & $73.2 \pm 11.1$ & $25 \pm 11.8$ & $<0.01$ \\
\hline $\begin{array}{c}\text { CGS-19755, } \\
100 \mu \mathrm{M}\end{array}$ & $97.7 \pm 3.7$ & $40.3 \pm 11.9$ & $<0.001$ \\
\hline $\begin{array}{l}\text { Low chloride, } \\
\text { low calcium }\end{array}$ & $92.2 \pm 8.5$ & $18.9 \pm 9.6$ & $<0.001$ \\
\hline Hypothermia & $\begin{array}{l}37^{\circ} \mathrm{C} \\
78.8 \pm 9.2\end{array}$ & $\begin{array}{l}33^{\circ} \mathrm{C} \\
1.1 \pm 0.77\end{array}$ & $<0.001$ \\
\hline PBN, $100 \mu \mathrm{M}$ & $50.4 \pm 13.3$ & $15.5 \pm 8.9$ & 0.04 \\
\hline
\end{tabular}

Data illustrate the effect of neuroprotective strategies in reducing the percentage fluorescence, used as an indicator of neuronal damage, in the CA1 region of the hippocampal slice cultures caused by severe oxygen and glucose deprivation. The NMDA antagonists MK-801, APV, CGS-19755, and also hypothermia, low chloride and low calcium in the buffer during the insult, and the free radical spin trapping compound $\mathrm{PBN}$ all provided significant protection to CA1 against damage from this insult (Student's $t$ test) (all values given as mean $\pm \mathrm{SEM} ; n=12$ for each group).

period (40 $\mathrm{min}$ ) produced more neuronal damage and neither were affected by NMDA receptor blockade using MK-801 (30 $\mu \mathrm{M}$ ) (Fig. 6A). The AMPA/kainate receptor antagonist CNQX $(300 \mu \mathrm{M})$, was also not neuroprotective against this insult when administered alone, or in combination with $\mathrm{MK}-801(30 \mu \mathrm{M})$ or APV $(300 \mu \mathrm{M})$ (Table 3).

To ensure that the high glucose used in the culture medium (33.6 $\mathrm{mM}$ ) was not responsible for the lack of protection seen with NMDA receptor blockade, we performed an additional experiment with the glucose reduced from $33.6 \mathrm{~mm}$ to a more physiological concentration, $5.6 \mathrm{~mm}$, in the HBSS during the complete oxygen deprivation. Under these conditions, MK-801 $(30 \mu \mathrm{M})$ still did not provide any protection against two different severities of neuronal damage induced by complete oxygen de-

Table 3. Effect of neuroprotective strategies on CA1 damage (\% fluorescence) induced by complete oxygen deprivation

\begin{tabular}{|c|c|c|c|}
\hline & Control & Treated & $p$ value \\
\hline MK-801, $30 \mu \mathrm{M}$ & $66.4 \pm 9.2$ & $67.9 \pm 9.3$ & 0.88 \\
\hline APV, $300 \mu \mathrm{M}$ & $43.0 \pm 13$ & $63.1 \pm 8.9$ & 0.17 \\
\hline CNQX, $300 \mu \mathrm{M}$ & $52.2 \pm 10$ & $64.0 \pm 6.3$ & 0.21 \\
\hline $\begin{array}{l}\mathrm{APV}, 300 \mu \mathrm{M}+ \\
\mathrm{CNQX}, 300 \mu \mathrm{M}\end{array}$ & $57.9 \pm 9.4$ & $73.6 \pm 8.7$ & 0.14 \\
\hline $\begin{array}{c}\mathrm{MK}-801,30 \mu \mathrm{M}+ \\
\text { CNQX, } 300 \mu \mathrm{M}\end{array}$ & $89.0 \pm 1.9$ & $79.2 \pm 5.5$ & 0.1 \\
\hline $\begin{array}{l}\text { Low chloride, } \\
\text { low calcium }\end{array}$ & $92.6 \pm 8.5$ & $21.6 \pm 3.6$ & $<0.001$ \\
\hline Hypothermia & $65.6 \pm 9.7$ & $6.0 \pm 1.9$ & $<0.001$ \\
\hline PBN, $100 \mu \mathrm{M}$ & $49.6 \pm 11.6$ & $5.7 \pm 3.2$ & 0.003 \\
\hline
\end{tabular}

Data demonstrate the effect of neuroprotective strategies in reducing the percentage fluorescence, used as an indicator of neuronal damage, in the CA region of the hippocampal slice cultures caused by severe oxygen deprivation, with glucose present $(33.6 \mathrm{~mm})$. In contrast to the protective effect seen with oxygen and glucose deprivation, glutamate receptor blockade using the NMDA antagonists MK-801 or APV, alone or in combination with the AMPA/kainate receptor antagonist CNOX, did not reduce neuronal damage caused by severe anoxia. There was also no reduction in anoxia-induced CA 1 damage by CNQX alone. Hypothermia, low chloride and low calcium in the buffer during the insult, and the free radical spin trapping compound PBN all provided significant protection to CA1 against damage from this insult (Student's $t$ test) (all values given as mean $\pm \mathrm{SEM} ; n=12$ for each group).

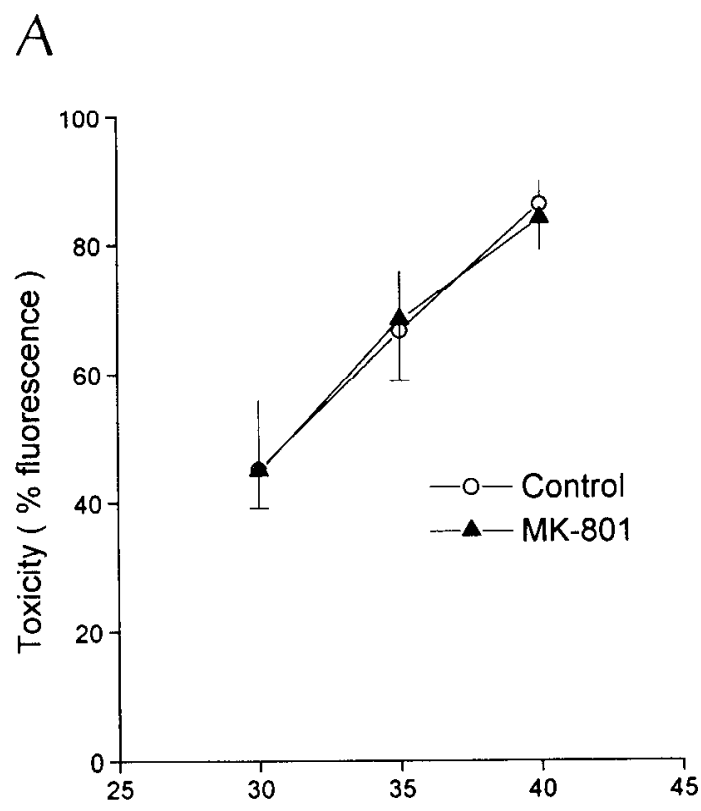

Time in Anoxic Conditions (minutes)

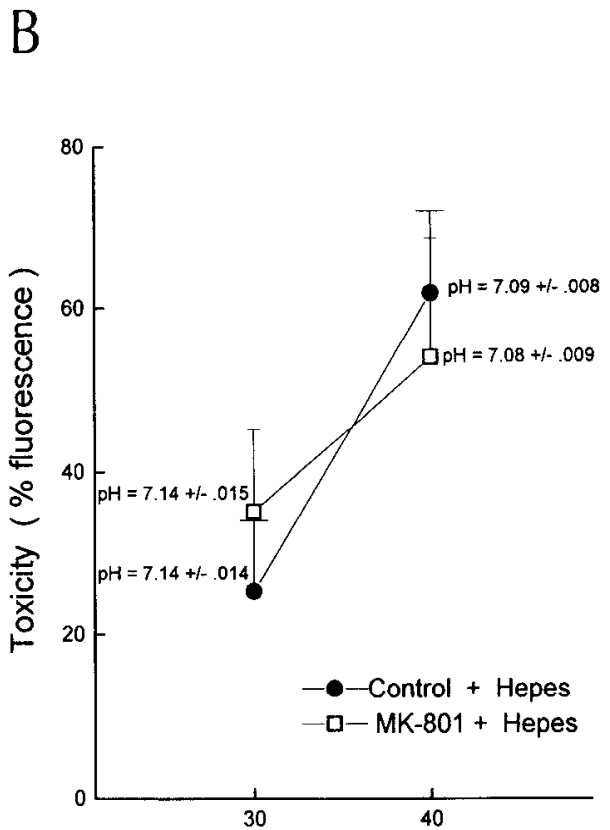

Time in Anoxic Conditions (minutes)

Figure 6. Effect of MK-801 on complete oxygen deprivation with glucose $(33.6 \mathrm{mM})$ present. $A, \mathrm{MK}-801(30 \mu \mathrm{M})$ does not prevent damage of varying severity to CA1 produced by exposure to complete oxygen deprivation (anoxia) for 30,35 , and $40 \mathrm{~min}$, in HBSS with bicarbonate buffer only. $B$, There was also no significant effect of MK-801 $(30 \mu \mathrm{M}) 30$, or $40 \mathrm{~min}$ of complete oxygen deprivation in HBSS with bicarbonate and $10 \mathrm{~mm}$ Hepes buffer which was initially adjusted to $\mathrm{pH}$ 7.4. The $\mathrm{pH}$ values shown on the illustration were those measured in the culture wells at the end of the anoxic exposure (values were not significantly different using Mann-Whitney $U$ test with Bonferroni correction. $n=12$ each group). 


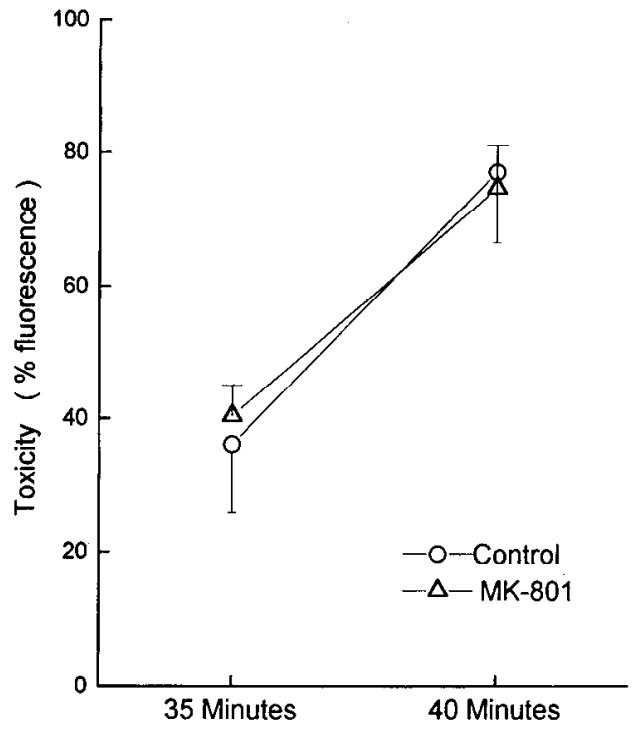

Figure 7. Effect of MK-801 ( $30 \mu \mathrm{M})$ on CAl damage caused by complete oxygen deprivation at two different severity levels (35 and 40 min) with $5.6 \mathrm{~mm}$ glucose present. There is no significant difference at either level of injury $(p=0.71$ at $35 \mathrm{~min}, p=0.85$ at $40 \mathrm{~min}$, by $t$ test). The results indicate that the lack of protection by NMDA receptor blockade against severe oxygen deprivation cannot be explained by the higher glucose concentration used in the other experiments.

privation for 35 or $40 \mathrm{~min}$ (Fig. 7). These results indicate that the higher glucose concentration is not responsible for the lack of protection by NMDA blockade. We also tested CNQX for protective effect against damage by complete oxygen deprivation (between 35 and $40 \mathrm{~min}$ ) with $5.6 \mathrm{~mm}$ glucose present, and found no significant protection (controls $=81.44 \pm 7.8 \%, 300$ $\mu \mathrm{M}$ CNQX $=91.3 \pm 1.9 \%$ fluorescence, $n=10, p=0.12$ ).

Since we did not find any protection against complete oxygen deprivation using glutamate antagonists, we then examined the effects of other neuroprotective strategies which act primarily through non-glutamate dependent mechanisms. As with oxygen plus glucose deprivation, hypothermia $\left(33^{\circ} \mathrm{C}\right)$, low calcium and chloride, and the free radical scavenger PBN $(100 \mu \mathrm{M})$ all provided significant protection against complete oxygen deprivation (Table 3).

NMDA receptor function is inhibited by low pH (Tang et al., 1990; Kaku et al., 1993). Extracellular pH typically was about 6.5 with complete oxygen deprivation, and could potentially account for the lack of NMDA mediated protection against this insult. We therefore supplemented the HBSS with $10 \mathrm{~mm}$ Hepes

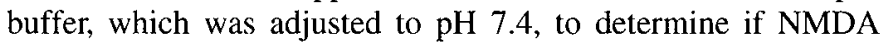
receptor blockade would provide neuronal protection against anoxia at a higher $\mathrm{pH}$. There was also no protection provided by MK-801 $(30 \mu \mathrm{M})$, against two severity levels of damage induced by complete oxygen deprivation (glucose, $33.6 \mathrm{~mm}$ ), when tested at $\mathrm{pH}=7.4$ (all culture wells were adjusted to $\mathrm{pH}=7.4$ prior to oxygen deprivation). The $\mathrm{pH}$ values in the buffer following anoxic exposure, and values for the damage in control and treated cultures are shown in Figure $6 B$.

Previous reports have indicated that NMDA receptor blockade has been effective in providing neuronal protection against partial oxygen deprivation (Goldberg et al., 1987; Marcoux et al., 1990). Since the present experiments and reports by other investigators (Aitken et al., 1988; Lipton and Lobner, 1990; Freidman and Haddad, 1993) have indicated that NMDA antagonists
Table 4. Effect of NMDA receptor blockade on CA1 damage (\% fluorescence) induced by partial substrate deprivation and glutamate exposure

\begin{tabular}{|c|c|c|c|}
\hline \multirow[b]{2}{*}{ Insult and exposure time } & \multicolumn{2}{|c|}{$\%$ CA1 damage } & \multirow[b]{2}{*}{$p$ value } \\
\hline & Control & $\begin{array}{l}\text { MK-801 } \\
(30 \mu \mathrm{M})\end{array}$ & \\
\hline $\begin{array}{l}\text { Partial oxygen deprivation } \\
\left(4 \% \mathrm{O}_{2} \text { with glucose }\right. \\
\text { present, } 2 \mathrm{hr})\end{array}$ & $56.0 \pm 8.8$ & $22.0 \pm 8.6$ & 0.01 \\
\hline $\begin{array}{l}\text { Partial oxygen and complete } \\
\text { glucose deprivation } \\
\left(4 \% \mathrm{O}_{2} \text { without glucose, }\right. \\
1 \mathrm{hr})\end{array}$ & $52.0 \pm 13.2$ & $9.9 \pm 5.7$ & 0.007 \\
\hline $\begin{array}{l}\text { Glucose deprivation } \\
\text { (no glucose, } 2.5 \mathrm{hr} \text { ) }\end{array}$ & $61.7 \pm 6.7$ & $11.5 \pm 8.2$ & $<0.001$ \\
\hline $\begin{array}{l}\text { Glutamate exposure } \\
(10 \mathrm{~mm} \text { glutamate, } \\
30 \mathrm{~min})\end{array}$ & $47.3 \pm 8.4$ & $8.5 \pm 2.0$ & $<0.001$ \\
\hline
\end{tabular}

Data demonstrate the significant protective effect of NMDA receptor blockade using MK-801 in reducing the percentage fluorescence, used as an indicator of Ineuronal damage, in the CAl region of the hippocanoal slice cultures caused by partial oxygen deprivation $\left(4 \% \mathrm{O}_{2}\right)$ without and with glucose $(33.6 \mathrm{mM})$, glucose deprivation with oxygen present, and exposure to glutamate $(10 \mathrm{~mm})$ for $30 \mathrm{~min}$ (Student's $t$ test) (all values given as mean $\pm \mathrm{SEM} ; n=12$ for each group).

are ineffective in reducing neuronal injury from severe oxygen deprivation, we studied the effect of NMDA receptor blockade on neuronal injury induced by partial oxygen deprivation. We exposed the hippocampal slice cultures to a longer period of less severe oxygen deprivation in order to produce an equivalent degree of injury caused by $35 \mathrm{~min}$ of complete oxygen deprivation.

\section{Partial oxygen deprivation (hypoxia)}

Partial oxygen deprivation produced by placing cultures in an environment of $4 \%$ oxygen, in glucose containing HBSS, required $2 \mathrm{hr}$ of exposure time to produce significant neuronal damage in CA1. Blockade of NMDA receptors using MK-801 $(30 \mu \mathrm{M})$ significantly reduced neurotoxicity in CA1 caused by this insult (see Table 4).

We then examined the effect of NMDA receptor blockade on CA1 damage caused by partial oxygen deprivation combined with glucose deprivation, as well as glucose deprivation alone, and also damage caused by addition of glutamate.

\section{Glucose deprivation with partial oxygen deprivation}

Partial oxygen deprivation, using. $4 \%$ oxygen, combined with complete glucose deprivation required only half the exposure time $(1 \mathrm{hr})$ to produce equivalent damage to CA1 neurons as the same level of oxygen deprivation with glucose present. Exposure to this insult for $1 \mathrm{hr}$ produced neuronal degeneration in CA1. Significant neuronal protection was observed in the presence of MK-801 ( $30 \mu \mathrm{M})$, indicated by a marked reduction in CA1 fluorescence (see Table 4).

\section{Glucose deprivation}

Deprivation of glucose produced by incubating the cultures in glucose free medium required $2.5 \mathrm{hr}$ also produced CAl damage. There was also prominent dentate damage observed with this insult. Blockade of NMDA receptors with MK-801 (30 $\mu \mathrm{M})$ significantly reduced fluorescence in CAl (see Table 4). 


\section{Glutamate toxicity}

Addition of glutamate $(10 \mathrm{~mm})$ to the culture medium for 30 caused marked neuronal damage to all the hippocampal subfields, when examined 40-48 hr later. Blockade of NMDA receptors using MK-801 (30 $\mu \mathrm{M})$ significantly reduced delayed fluorescence in CAl caused by the glutamate (see Table 4).

\section{Discussion}

These results indicate that there are different mechanisms that produce neuronal damage during severe anoxia in the presence or absence of glucose. Glutamate receptor mediated neurotoxicity appears to be an important component of neuronal injury under in vitro conditions when neurons are deprived of oxygen and glucose. With severe oxygen deprivation in the presence of glucose however, neuronal injury occurs which is not prevented by glutamate antagonists, but can be prevented using other strategies which provide neuroprotection primarily through other mechanisms.

These findings are in agreement with previous findings from other laboratories using dissociated neuronal cultures, or acutely prepared hippocampal slices. NMDA receptor antagonists have not been found to provide neuroprotection in these models against severe oxygen deprivation (Aitken et al., 1988; Lipton and Lobner, 1990; Friedman and Haddad, 1993). but do provide protection against combined oxygen and glucose deprivation (Newell et al., 1990, 1995; Goldberg and Choi, 1993; Kaku et al., 1993; Vornov at al., 1994). NMDA receptor blockade is ineffective in preventing intraneuronal calcium accumulation, which is associated with delayed neuronal death (Seisjo and Bengtsson, 1989; Hartly et al., 1993), due to severe anoxia alone. Lipton and Lobner (1990) also showed in acutely prepared hippocampal slices exposed to complete oxygen deprivation, that NMDA receptor blockade failed to block increases in intracellular calcium levels. Using dissociated cell cultures, Friedman and Haddad (1993) found that severe anoxia caused a rapid increase in intracellular calcium in neurons which was also not prevented by combined NMDA and non-NMDA receptor blockade using MK-801 and CNQX. NMDA antagonists are reported to reduce neuronal damage produccd by extremely long exposures $(8 \mathrm{hr}$ ) to low oxygen (Goldberg et al., 1987). Due to the experimental design of this study, in which the neuronal cultures were submerged in buffer, it was stated that initial oxygen deprivation was probably partial. We have also found a delay $(15-20 \mathrm{~min})$ in the reduction in oxygen concentration in cultures submerged in $1.5 \mathrm{ml}$ of buffer (data not shown). However, no delay was observed in this study, when interface cultures were used (Fig. 1). Similarly, Marcoux et al. (1990) demonstrated that NMDA receptor blockade reduced calcium accumulation in dissociated neurons exposed to a $1 \%$ oxygen environment for $5 \mathrm{hr}$. These results are consistent with our finding that NMDA receptor blockade can protect neurons against oxygen deprivation alone of reduced severity (4\% oxygen for $2 \mathrm{hr}$ in the present study).

The mechanism responsible for the different protective effects of NMDA rcceptor blockade against neuronal damage produced by severe oxygen deprivation alone and severe combined oxygen and glucose deprivation, is unclear. The two insults cause a similar degree of injury in this system. Increased intracellular calcium is thought to play an important role in the pathogenesis of ischemic neuronal damage (Andine at al., 1988; Seisjo and Bengtsson 1989; Lobner and Lipton 1993). It has been proposed that NMDA antagonists cannot effectively prevent increased intracellular calcium in severe ischemia due to massive neuronal depolarization and ATP depletion (Wieloch et al., 1989; Seisjo, 1992). Under these circumstances, calcium may enter cells through a variety of pathways, and energy dependent calcium extrusion mechanisms can fail (Kass, 1982; Lipton and Lobner, 1990; Seisjo, 1992; Lobner and Lipton, 1993). This explanation could account for the differences observed between complete oxygen deprivation and the more prolonged insults in our experiments, however it would not explain why NMDA antagonists protect against damage induced by complete oxygen and glucose deprivation which should cause the most marked energy deprivation.

Another possible explanation for the present findings is that oxygen deprivation in the presence of glucose may induce anaerobic metabolism, which could lower $\mathrm{pH}$. At low $\mathrm{pH}$, NMDA receptors can be inactivated (Giffard et al., 1990; Tang et al., 1990; Kaku et al., 1993), and under these circumstances lactate accumulation may occur, and other mechanisms of cell toxicity may predominate. Kaku et al. (1993) found that although a lower extracellular $\mathrm{pH}$ provided a protective effect against damage to dissociated neuronal cultures deprived of oxygen and glucose, the addition of glutamate antagonists provided additional protection against this insult at a pH of 6.4. This was lower than the $\mathrm{pH}$ in the buffer solution following complete oxygen or oxygen and glucose deprivation in our experiments. Measurement of the $\mathrm{pH}$ in the HBSS immediately following each of these insults revealed only a slightly lower $\mathrm{pH}$ in our cultures exposed to oxygen deprivation alone versus those exposed to combined oxygen and glucose deprivation (6.63 vs 6.77). We cannot, however, conclude from our measurements that the $\mathrm{pH}$ did not reach lower levels in the intracellular compartment, or in the extracellular space microenvironment in the cultures undergoing complete oxygen deprivation. When we raised the $\mathrm{pH}$ using $\mathrm{He}$ pes buffered solutions, there was still no protection provided by MK-801 to damage induced by complete oxygen deprivation. The $\mathrm{pH}$ measured following oxygen deprivation in these experiments was 7.1 , which should not cause marked NMDA receptor inactivation.

The glucose concentration used for maintaining hippocampal slice cultures is $33.6 \mathrm{~mm}$ in the growth medium and was the same concentration in the HBSS with glucose used for these experiments. To determine if the lack of protection with NMDA blockade was due to "hyperglycemic" conditions, which may worsen the acidosis produced during exposure, we repeated the anoxia experiment in HBSS containing a normal physiologic glucose concentration (5.6 mM). NMDA receptor blockade was still not effective in reducing neuronal damage of two different severity levels, caused by complete oxygen deprivation at this glucose concentration.

Other neuroprotective strategies which do not act primarily through glutamate receptors, did not exhibit similar differential neuroprotection between complete oxygen, and oxygen/glucose deprivation. These neuroprotective strategies included hypothermia, low chloride plus low calcium, and also free radical scavenging using PBN, and were all strongly neuroprotective in our model against CA1 damage induced by either combined oxygen and glucose deprivation or oxygen deprivation with glucose present. The neuronal protective effects of these treatments probably involves multiple mechanisms. Hypothermia has been shown to reduce ischemia induced glutamate release (Busto et al., 1989; Maher and Haschinski, 1993), as well as to preserve 
high energy phosphates during ischemia (Sutton et al., 1991) and thus preserve energy dependent calcium extrusion mechanisms (Kass and Lipton, 1982; Lipton and Lobner 1990). The involvement of ion fluxes in ischemic neuronal damage is supported by the neuroprotective effect of decreased chloride and calcium in the buffer solution during oxygen deprivation alone as well as by oxygen/glucose deprivation (Rothman, 1985; Goldberg et al., 1986; Friedman and Iladdad, 1993). Decreased calcium in the extracellular fluid may attenuate the intracellular calcium surge seen with neuronal depolarization caused by energy deprivation through multiple mechanisms (Schurr and Rigor, 1992; Seisjo, 1992), and also can protect against glutamate neurotoxicity (Choi, 1985, 1987). We used sodium gluconate to replace chloride with a nonpermeant anion, which has been shown by others to inhibit neuronal swelling due to depolarization (MacVicker and Hochman, 1991). Recently, increased production of free radicals has been reported to lead to membrane breakdown, and damage to cellular organelles resulting in cell death following ischemia (Seisjo, 1992; Dawson et al., 1993; Sen and Phillis, 1993). Increases in intracellular calcium are thought to increase nitric oxide levels which can lead to excess free radical production (Seisjo, 1992; Dawson et al., 1993; Dawson, 1994). Free radical spin trapping compounds such as PBN can reduce frec radical levels, and have been shown to provide neuroprotection in an in vivo model (Clough-Helfman and Phillis, 1991; Sen and Phillis, 1993). The fact that these strategies were protective following both glutamate receptor mediated, and non-glutamate receptor mediated neuronal injury, suggests that they may influence separate common pathways leading to cell damage.

NMDA antagonists have been effective in reducing infarct size in focal ischemia models, suggesting that these compounds protect against partial energy deprivation which occurs in the ischemic penumbra (Wieloch et al., 1989; Seisjo, 1992). NMDA receptor blockade has also been reported to reduce neuronal injury with partial oxygen (Goldberg et al., 1987; Marcoux et al., 1990). We therefore investigated the effects of NMDA receptor blockade on incomplete oxygen and glucose deprivation. These insults included glucose deprivation alone, partial oxygen deprivation $\left(4 \% \mathrm{O}_{2}\right)$, and partial oxygen deprivation $\left(4 \% \mathrm{O}_{2}\right)$, with complete glucose deprivation. The time of exposure was increased using each of these insults to attempt to induce a similar degree of damage which was observed after 35 min of complete oxygen and glucose deprivation. We found that NMDA receptor blockade effectively reduced neuronal injury produced by more prolonged exposure to insults which caused less severe energy deprivation, than complete oxygen and glucose deprivation (Table 4).

These experiments confirm that NMDA receptor antagonists can reduce $\mathrm{CA} 1$ injury caused by oxygen and glucose deprivation. These results also indicate that the presence of glucose during severe oxygen deprivation prevents the reduction of neuronal injury by glutamate receptor blockade. It remains to be elucidated why the presence of glucose prevents glutamate receptor blockade from reducing neuronal injury from severe anoxia. It is known that clinical situations exist such as anoxia from suffocation, carbon monoxide poisoning or other conditions where the cerebral circulation continues to supply glucose to the brain in the absence of oxygen. If the results from these experiments are directly applicable to these clinical situations, they may indicate that glutamate receptor blockade would be ineffective in reducing neuronal injury produced by insults where severe anoxia predominates. Further experiments using in vivo models are needed to determine if our results apply to these clinical situations.

\section{References}

Aitken PG, Balestrino M, Somjen GG (1988) NMDA antagonists: lack of protective effect against hypoxic damage in CAl region of hippocampal slices. Neurosci Lett 89:187-192.

Andine P, Jacobson I, Hagberg H (1988) Calcium uptake evoked by electrical stimulation is enhanced post-ischemically and precedes delayed neuronal death in CAI of rat hippocampus: involvement of $\mathrm{N}$-methyl-D-aspartate receptors. J Cereb Blood Flow and Metab 8:799-807

Benveniste H, Drejer J, Schousboe A, Diemer N (1984) Elevation of the extracellular concentrations of glutamate and aspartate in rat hippocampus during transient cerebral ischemia monitored by intracerebral microdialysis. J Neurochem 43:1369-1374.

Bolender RP, Charlston J, Mottet K, McCabe JT (1991) Quantitative morphology of the nervous system: expanding horizons. Anat Rec 231:407-415.

Brown AW, Brierly JB (1972) Anoxic-ischemic cell change in rat brain light microscopic and fine-structural observations. J Neurol Sci 16 59-84

Buchan AM (1990) Do NMDA antagonists protect against cerebral ischemia: are clinical trials warranted? Cerebrovasc Brain Metab Kev 2:1-26.

Buchan A, Pulsinelli W (1990) Hypothermia but not the $N$-methyl-Daspartate antagonist, MK-801, attenuates neuronal damage in gerbils subjected transient global ischemia. J Neurosci 10:311-316.

Buchan AM, Li H, Cho S, Pulsinelli WA (1991) Blockade of the AMPA receptor prevents CA1 hippocampal injury following severe but transient forebrain ischemia in adult rats. Neurosci Lett 132:255258.

Busto R, Globus MY-T, Dietrch WD, Martinex E, Valdes I, Ginsberg MD (1989) Effect of mild hypothermia on ischemia-induced release of neurotransmitters and free fatty acids in rat brain. Stroke 20:904910.

Choi DW (1985) Glutamate neurotoxicity in cortical cultures is calcium dependent. Neurosci Lett 58:293-29'.

Choi DW (1987) Ionic dependence of glutamate neurotoxicity. J Neurosci 7:369-379.

Choi DW (1990) Methods for antagonizing glutamate neurotoxicity. Cerebrovasc Brain Metab Rev 2:105-147.

Clark GD, Rothman S (1987) Blockade of excitatory amino acid receptors protects anoxic hippocampal slices. Neuroscience 21:665671.

Clough-Helfman C, Phillis JW (1991) The free radical trapping agent $N$-tert-butyl- $\alpha$-phenylnitrone (PBN) attenuates cerebral ischemic injury in gerbils. Free Radical Res Comm 15:177-186.

Dawson DA (1994) Nilric oxide and focal cerebral ischenia: Multiplicity of actions and diverse outcome. Cerebrovasc Brain Metab Rev $6: 299-324$.

Dawson VL, Dawson TM, Bartly DA, Uhl GR, Snyder S (1993) Mechanisms of nitric oxide-mediated neurotoxicity in primary brain cultures. J Neurosci 13:2651-2661.

Faden AI, Demidiuk P, Panter SS, Vink R (1989) The role of excitatory amino acids and NMDA receptors in traumatic brain injury. Science 244:798-800.

Friedman JE, Haddad G (1993) Major differences in Ca response to anoxia between neonatal and adult rat $\mathrm{CAl}$ neurons: role of $\mathrm{Ca}$ and Na. J Neurosci 13:63 72.

Gahwiler B (1981) Organotypic monolayer cultures of nervous tissue. J Neurosci Methods 4:329-342.

Gahwiler BH (1984) Development of hippocampus in vitro: cell types, synapses and receptors. Neuroscience 11:751-776.

Gahwiler B (1988) Organotypic cultures of neural tissue. Trends Neurosci 1 1:484-489.

Germano IM, Pitts LH, Meldrum BS, Bartowski HM, Simon RP (1987) Kynurenate inhibition of cell excitation decreases stroke size and deficits. Ann Neurol 22:730-734.

Giffard RG, Monyer H, Christine CW, Choi DW (1990) Acidosis reduces NMDA receptor activation, glutamate neurotoxicity and oxygen-glucose deprivation neuronal injury in cortical cultures. Brain Res 506:339-342. 
Gill R, Foster A, Woodruff G (1987) Systemic administration of MK801 protects against ischemia-induced hippocampal neurodegeneration in the gerbil. J Neurosci 7:3343-3349.

Goldberg MP, Choi DW (1993) Combined oxygen and glucose deprivation in cortical cell culture: calcium-dependent and calcium-independent mechanisms of neuronal injury. J Neurosci 13:3510-3522.

Goldberg WJ, Kadingo RM, Barnett JN (1986) Effects of ischemialike conditions on cultured neurons: protection by low $\mathrm{Na}+$, low $\mathrm{Ca}++$ solutions. J Neurosci 6:3144-3151

Goldberg M, Weiss J, Pham P-C, Choi D (1987) $N$-methyl-D-aspartate receptors mediate hypoxic neuronal injury in cortical culture. J Pharmacol Exp Ther 243:784-791

Haddad GG, Jiang C (1993) Mechanisms of anoxia-induced depolarization in brainstem neurons: in vitro current and voltage clamp studies in the adult rat. Brain Res 625:261-268.

Hartley DM, Kurth MC, Bjerkness L, Weiss JH, Choi DW (1993) Glutamate receptor-induced ${ }^{45} \mathrm{Ca}^{2+}$ accumulation in cortical cell culture correlates with subsequent neuronal degeneration. J Neurosci 13: 1993-2000.

Hsu S, Newell DW, Tucker A, Malouf A, Winn HR (1994) Adenosinergic modulation of CA1 neuronal tolerance to glucose deprivation in organotypic hippocampal cultures. Neurosci Lett 178:189-192.

Iohansen F, Jorgenson M, Diemer N (1986) Ischemic CA1 pyramidal cell loss is prevented by preischemic colchicine destruction of dentate gyrus granule cells. Brain Res 377:344-347.

Jorgenson MB, Johansen FF, Diemer N (1987) Removal of the entorhinal cortex protects $\mathrm{CA} 1$ neurons from ischemic damage. Acta Neuropathol (Berl) 73:189-194.

Kaku DA, Giffard RG, Choi DW (1993) Neuroprotective effects of glutamate antagonists and etracellular acidity. Science 260:15161518.

Kass IS, Lipton P (1982) Mechanisms involved in irrevesible anoxic damage to the in vitro rat hippocampal slice. J Physiol (Lond) 332: $459-472$.

Katayama Y, Becker DP, Tamura T, Hovda DA (1990) Massive increases in extracellular potassium and the indiscriminate release of glutamate following concussive brain injury. J Ncurosurg 73:889900.

Lehmann J, Chapman AG, Meldrum BS, Hutchison A, Tsai C, Wood PL (1988) CGS 19755 is a potent and competitive antagonist at NMDA-type receptors. Eur J Pharmacol 154:89-93.

Lipton P, Lobner D (1990) Mechanism of intracellular calcium accumulation in the CA1 region of rat hippocampus during anoxia in vitro. Stroke 21(Suppl III):60-64.

Lobner D, Lipton P (1993) Intracellular calcium levels and calcium fluxes in the CA1 region of the rat hippocampal slice during in vitro ischemia: relationship to electrophysiological cell damage. J Neurosci 13:4861-4871.

Macklis JD, Madison RD (1990) Progressive incorporation of propidium iodide in clutured mouse neurons correlates with declinig electrophysiologic status: a fluorescence scale of membrane integrity. $\mathbf{J}$ Neurosci Methods 31:43-46.

MacVicar BA, Hochman D (1991) Imaging of synaptically evoked intrinsic optical signals in hippocampal slices. J Neurosci 11:14581469.
Maher J, Hachinski V (1993) Hypothermia as a potential treatment for cerebral ischemia. Cerebrovasc Brain Metab Rev 5:277-300.

Marcoux FW, Probert AW Jr, Weber ML (1990) Hypoxic neuronal injury in tissue culture is associated with delayed calcium accumulation. Stroke 21(Suppl III):71-74.

Meldrum B (1990) Protection against ischaemic neuronal damage by drugs acting on excitatory neurotransmission. Cerebrovasc Brain Metab Rev 2:27-57.

Newell DW, Malouf AT, Franck J (1990) Glutamate mediated selective vulnerability to ischemia is present in organotypic cultures of hippocampus. Neurosci Lett 116:325-330.

Newell DW, Barth A, Malouf AT (1995) Glycine site NMDA receptor antagonists provide protection against ischemia-induced neuronal damage in hippocampal slice cultures. Brain Res 675:38-44.

Onodera H. Sato G, Kogure K (1986) Lesions to Schaeffer collaterals prevent ischemic death of CA1 pyramidal cells. Neurosci Lett 68: 169-174.

Rothman SM (1985) The neurotoxicity of excitatory amino acids is produced by passive chloride influx. J Neurosci 5:1483-1489.

Schurr A, Rigor BM (1992) The mechanism of cerebral-hypoxic ischemic damage. Hippocampus 2:221 228.

Sen S, Phillis J (1993) Alpha-phenyl-tert-butyl nitrone (PBN) attenuates hydroxl radical production during ischemia-reperfusion injury of rat brain: an EPR study. Free Radical Res Comm 19:255-265.

Siesjo B (1992) Pathophysiology and treatment of focal cerebral ischemia. II. Mechanisms of damage and treatment. J Neurosurg 77:337354.

Siesjo B, Bengtsson F (1989) Calcium fluxes, calcium antagonists, and calcium related pathology in brain ischemia, hypoglycemia and spreading depression: a unifying hypothesis. J Cereb Blood Flow Metab 9:127-140.

Stoppini L, Buchs P-A, Muller D (1991) A simple method for organotypic cultures of nervous tissue J Neurosci Methods 37:173-182.

Sutton LN, Clark BJ, Norwood CR, Woodford EJ, Welsh FA (1991) Global cerebral ischemia in piglets under conditions of mild and deep hypothermia. Stroke 22:1567-1573.

Tang CM, Dichter M, Morad M (1990) Modulation of the $N$-methylD-aspartate channel by exxtracellular $\mathrm{H}^{+}$. Proc Natl Acad Sci USA 87:6445-6449.

Torp R, Haug FM, Tonder N (1992) Neuroactive amino acids in organotypic slice cultures of the rat hippocampus: an immunocyto chemical study of the distribution of GABA, glutamate, glutamine and taurine. Neurosci 46:807-823.

Vornov JJ, Tasker RC, Coyle JT (1991) Direct observation of the agonist-specific regional vulnerability to glutamate, NMDA, and kainate neurotoxicity in organotypic hippocampal cultures. Exp Neurol 114: $11-22$.

Vornov JJ, Tasker RC, Coyle JT (1994) Delayed protection by MK801 and Tetrodotoxin in a rat organotypic hippocampal culture model of ischemia. Stroke 25:457-465.

Wieloch T, Gustafson I, Westerberg E (1989) The NMDA antagonist, MK-801 is cerebro-protective in situations where some energy production prevails but not under conditions of complete energy deprivation. J Cereb Blood Flow Metab 9(Suppl 1):S6.

Zimmer J, Gahwiler BH (1984) Cellular and connective organization of slice cultures of the rat hippocampus and fascia dentata. J Comp Neurol 228:432-446. 